\title{
SOLUBILITY ENHANCEMENT METHODS WITH IMPORTANCE OF HYDROTROPY
}

\author{
Md. Ali Sajid *, Vicky Choudhary \\ School of Pharmaceutical Sciences, Shoolini University, Solan (H.P.), India \\ *Corresponding author's E-mail:sajidalipharma4u@gmail.com.Phone-09882840234
}

Received 13 Oct 2012; Review Completed 26 Oct 2012; Accepted 01 Nov 2012, Available online 15 Nov 2012

\begin{abstract}
The effectiveness of formulation depends particularly on how efficiently is drug available at the site of action. Therapeutic effectiveness of a drug basically depends upon bioavailability and the solubility of drug moiety. Most of the chemical entities that are being discovered are lipophilic and have poor aqueous solubility. A more than $40 \%$ drug suffers from poor water solubility. Currently number of techniques addressed the enhancement of solubility and dissolution rate of poorly soluble drugs. Hydrotropic solubilization is one of them. Hydrotropy is a solubilization phenomenon whereby addition of large amounts of a second solute results in an increase in the aqueous solubility of another solute. A hydrotrope is a compound that solubilises hydrophobic compounds in aqueous solution. To solubilize water insoluble drugs especially in case of oral formulation, solubility remains a critical factor so for in this review various solubility enhancement techniques are highlighted and a brief review of hydrotropy and its preparation are discussed.

Keywords: Solubility, Hydrotropy, Mixed hydrotropy
\end{abstract}

\section{INTRODUCTION}

The important phenomenon in pharmaceutical formulation is "solubility" which plays very effective and significant role in the formulation of various dosage forms. Solubility of a compound in a particular solvent is defined as the concentration of a solute in a saturated solution at a certain temperature. ${ }^{1}$

The solubility of a drug molecule may be critical factor determining its usefulness since the solubility dictates the amount of compound that will dissolve and therefore the amount available for absorption. If a compound has low water solubility it may be subject to dissolution rate limited absorption within the gastrointestinal residence time. In biopharmaceutical terms the solubility importance has been highlighted by Biopharmaceutical Classification System (BCS) described by Amidon in 1995 which classified the drugs into the four groups as shown in Table1. ${ }^{2}$

The key parameters on which BCS of a drug depends upon are solubility and permeability, solubility play an important role for the absorption of drugs. ${ }^{3}$

Table 1: The Biopharmaceutical classification system for drugs ${ }^{4}$

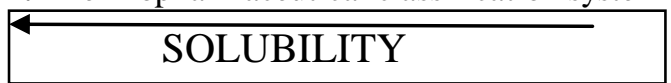

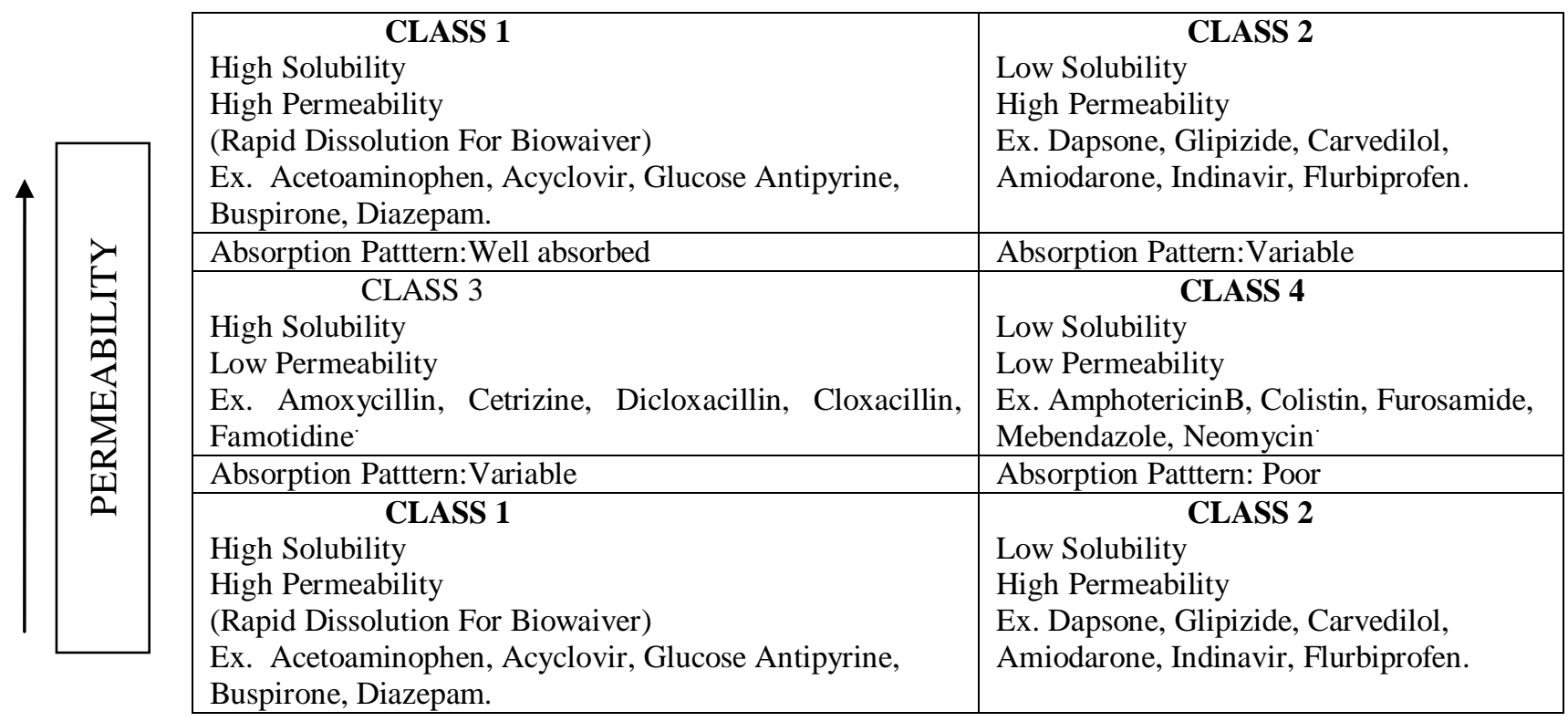

\section{EXPRESSING SOLUBILITY AND CONCENTRATION}

The Solubility is usually expressed by variety of concentration that is by Quantity per quantity, Percentage, Parts, Molarity, Molality, Mole fraction, Milliequivalents and normal solutions. ${ }^{5}$ This is also explained in term of parts of solvent required for 1 part of solute as explained in U. S pharmacopeia which is shown in Table 2. 
Table 2: Examples of drugs with their solubility ${ }^{6,7,8,9}$

\begin{tabular}{|l|l|l|}
\hline Terms & Parts of solvent required for 1 part of solute & Examples of drugs \\
\hline Very soluble & Less than 1parts & Metoprolol, Deltiazam \\
\hline Freely soluble & From 1-10 parts & Ipratropium bromide \\
\hline Soluble & From 10-30 parts & $\begin{array}{l}\text { Cyclophosphamide, carmustine, Quinidine, } \\
\text { Procainamide, Propananolol, Timolol }\end{array}$ \\
\hline Sparingly soluble & From 30-100 parts & $\begin{array}{l}\text { Fluorouracil, Quinidine Sulphate, Labetolol, } \\
\text { Ramipril }\end{array}$ \\
\hline Slightly soluble & From 100-1000 parts & Fludrabine, Atenolol, Valsartan \\
\hline Very slightly soluble & From 1000-10,000 parts & Busulphan, lomustine, Flecainide, Doxazocine \\
\hline Practically Insoluble & More than 10,000 parts & $\begin{array}{l}\text { Chlorambucil, Melphlan, Lidocaine, } \\
\text { Candesartan, Irbesartan, Nifedipine }\end{array}$ \\
\hline
\end{tabular}

\section{SOLUBILITY ENHANCEMENT TECHNIQUES}

\section{NANONIZATION ${ }^{10}$}

It is a technique where a drug particle is converted into nanocrystals having size range of 200-600nm. Pearl milling, homogenization in water, homogenization in non aqueous media is currently used technologies for preparing nanocrystals.

\section{SUPERCRITICAL FLUID RECRYSTALLIZATION $(\mathrm{SCF})^{10}$}

Those fluids are referred to as supercritical fluids which are having temperature and pressure greater than its critical temperature and critical pressure so as they are acquire properties of both gas and liquid. The best example of this is carbon dioxide. SCF are highly compressible at critical temperatures and allows alteration in density and mass transport characteristics which determines its solvent power due to moderate changes in pressure. As the drug gets solubilized within SCF they can be recrystallized with reduced particle size of drug.

\section{USE OF SURFACTANTS ${ }^{11}$}

To enhance both permeability of drug and dissolution, the surfactants are used as absorption enhancers which fulfills the above criteria. The proposed mechanism is that the wetting is first primarily promoted and further there is penetration of dissolution fluid into solid drug particles. Solubility enhancement of poorly water soluble antimicrobial drug, enrofloxacin has been studied using a series of surfactants and co-solvents. Among the surfactants, ionic surfactants were preferred over the non ionic surfactants as they were better solubilizing agents. In case of anionic surfactants they possess highest solubility rates, considering example of sodium dodecyl sulphate which is an anionic surfactant was a better solubilizing agent than cetyltrimethyl ammonium bromide which is a cationic surfactant.

\section{EVAPORATIVE PRECIPITATION ${ }^{12}$}

In this technique there is a rapid phase separation for nucleation and growth of microparticles and nanoparticles of water insoluble drugs. In this low boiling solvent is selected and a suitable amount of drug is added to it and the resultant solution is passed and pumped through a inert tube which is heated to a temperature under pressure above the selected organic solvent boiling point and sprayed into the heated aqueous solution through a fine atomizing nozzle. Further the surfactants are added so as to optimize the particle size.

\section{MICRONIZATION ${ }^{13}$}

This process typically emphasize on the reduction of drug particle size so as to increase in surface area which (C) 2011, JDDT. All Rights Reserved directly enhances dissolution characteristics and bioavailability of drug. The size range of drug particles after this process is 1-10 microns. The commonly used methods are spray drying and fluid energy or jet mill (by attrition methods).

\section{SONOCRYSTALLISATION ${ }^{13}$}

This technique is successfully employed to reduce particle size by using ultrasound, is sonocrystallisation which is a novel approach by use of anti-solvents and liquid solvents. By adding these anti-solvents and liquid solvents, recrystalllization of poorly water soluble drugs occurs.

\section{HIGH PRESSURE HOMOGENIZATION ${ }^{13}$}

It is basically involves the use of high pressure with very high velocity by passing the crystalline drug aqueous dispersion through a narrow gap. The proposed mechanism for this process is by shear forces and cavitations due to which particles get disintegrated. In this homogenization process drug particle which are obtained is dependent on directly pressure, nature of drug substance and number of homogenization cycles undergone. It can be performed in two ways: either in water (that is in disso cubes) or in water reduced media (nanopure).

\section{NANOMORPH TECHNOLOGY (NT) ${ }^{13}$}

By use of NT low water soluble drug substances are converted into amorphous nanomorph from crystalline state. In this suspension of drug substance is prepared in a solvent which is mixed with other solvent in a chamber, due to this a conversion of drug suspension into a true molecular solution occur. Precipitation of drug substance is induced by the aqueous solution of polymer. These polymers play an important role in preventing of aggregation or growth and maintain their nanoparticulate state. The example is CAP, Calcium-phosphate based nanoparticles which improve the oral bioavailability of hormones and proteins.

\section{DRUG DISPERSION IN CARRIERS ${ }^{14,15,16,17,18}$}

It was first recognized in 1961 that by use of solid dispersion, enhanced dissolution and absorption of drug. This term typically refers to dispersion in an inert carrier by addition of active ingredients, which is prepared by either solvent method or fusion method or by fusion solvent method. The carriers for preparation of solid dispersions are hydrophilic in nature and generally used Poly Vinyl Pyrrolidine, Poloxamer 188, Polyethylene Glycol, Plasdone-S630 and sugar carriers such as lactose, 
sucrose and mannitol. Sometimes surfactants are also used such as Tween-80, Docusate sodium etc. The solubility of etoricoxib, allopurinol, meloxicam, olanzapine, Carbamazepine can be improved by solid dispersion using suitable hydrophilic carriers like etoricoxib with different sugar carriers, allopurinol with polyvinylpyrrolidone (PVP) K30, PVP K90 and polyethylene glycol (PEG) 4000 and PEG 6000, meloxicam with Poloxamer 188, carbamazepine with crospovidone and hydroxypropylmethylcellulose, olanzapine with pregelatinised starch and sodium starch glycollate.

\section{BY USE OF CO-SOLVENTS ${ }^{19}$}

By addition of co-solvents, solubility of poorly water soluble drugs can be improved. There is a dramatic change in the solubility of drugs by addition of organic co-solvent into the water. The co-solvents are having hydrogen acceptor or donor groups with a small hydrocarbon region. The hydrophobic hydrocarbon region usually interferes with the hydrogen bonding network of water which consequently reduces the intermolecular attraction of water while the hydrophilic hydrogen bonds ensures water solubility.

\section{CHEMICAL MODIFICATIONS ${ }^{20}$}

For increasing the aqueous solubility of poorly water soluble drugs, change in $\mathrm{pH}$ of a system is the simplest and most effective method. There is an exponential increase in the solubility of ionizable drug by changing the $\mathrm{pH}$ of solution. The drug which is to be efficiently solubilised should be a weak base with a high $\mathrm{pKa}$ value or weak acid with a low pKa value. The use of salt forms is a well known technique to enhanced dissolution profiles. Salt formation is the most common and effective method of increasing solubility and dissolution rates of acidic and basic drugs.

\section{CRYSTAL HABIT MODIFICATION ${ }^{20}$}

The property of a compound to exhibit in more than crystalline form is referred to as polymorphism. It is observed that they exhibit different physiochemical property such as stability, melting point, density etc. but are identical chemically.

\section{MOLECULAR ENCAPSULATION WITH CYCLODEXTRINS $^{21}$}

The unique property of cyclodextrins and their derivative is their ability to form molecular inclusion complexes with poorly water soluble drugs. These are usually having a hydrophobic cavity having enough space to accommodate "guest" molecules which are lipophilic in nature and oligosaccharide shaped bucket to hold this cavity. Thus the drugs get encapsulated in the cavity and results in improved aqueous solubility and enhance dissolution rates. Barbiturates and NSAIDS are examples with enhanced bioavailability.

\section{HYDROTROPIC SOLUBILISATION}

It is a technique firstly introduced by Neuberg (1916). ${ }^{20,22}$ It is a process where large amount of secondary solute added and as a results increased aqueous solubility of water insoluble drugs.

\section{MECHANISM OF ACTION OF HYDROTROPE}

Neubergs conventional hydrotropic salts generally consist of two parts, a hydrophobic aromatic ring or ring system and anionic group. The prerequisite for a hydrotropic substance is anionic group which is responsible for bringing high aqueous solubility. There is a minor effect on the type of anion or metal ion. On the flip side planarity of hydrophobic part also plays a crucial role in hydrotropic solubilisation mechanism. ${ }^{23}$ Those salts or additives which increases solubility in a given solvent are referred to as "salt in" and which decreases solubility are referred to as "salt out". Hydrotropism refers to as salting in of non electrolytes which are highly soluble in water. The mechanism involved in hydrotropy is related to complexation which involves interaction between lipophilic drugs and the hydrotropic agents such as urea, nicotinamide, sodium alginate, sodium benzoate etc. ${ }^{22}$

\section{ADVANTAGES OF HYDROTROPIC SOLUBILISATION}

- This process doesn't require emulsification, highly selective and solvent character is independent of $\mathrm{pH}$ so it is preferred over other solubilisation methods such as cosolvency, micellar solubilisation.

- It primarily involves the mixing of hydrotrope and drug directly into solvent which is water.

- It precludes the chemical modification of hydrophobic drugs or preparation of emulsion system.

Hydrotropes are having the ability to increase the solubility of poorly water soluble drug and this tendency is greatest when concentration of hydrotropes is sufficiently enough to form the associated structures. Minimum hydrotrope concentration is referred to concentration of hydrotrope at which self association occurs. Hydrotrope can be categorized according to their structure as shown in Table 3.

\section{METHOD OF PREPARATION OF HYDROTROPIC SOLID DISPERSION}

It is a relatively new technique in which the drug and selected hydrotropes are taken in different ratio in beaker, distilled water is added at a temperature ranging between $80-85^{\circ} \mathrm{C}$. Then the selected hydrotrope is taken and added to water. Then slowly add drug to the beaker and teflon coated magnetic bead is dropped in beaker, temperature is to be maintained for optimum stirring and stirring is continued until semisolid mass is obtained. This semisolid mass is spread on several watch glasses and is placed in oven maintaining a temperature of $60-65^{\circ} \mathrm{C}$. Then the trituration is done with pestle and mortar and after drying passes it through sieve no.100 and kept in desiccators for 6 days. Flow chart $1 .^{25,26}$ 
Table 3: Classification of Hydrotropes ${ }^{24}$

\begin{tabular}{|c|c|c|}
\hline Category & Examples & Structure \\
\hline \multirow[t]{8}{*}{ Aromatic anionics } & Sodium benzoate & \\
\hline & Sodium salicylate & \\
\hline & Sodium benzene sulphonate & \\
\hline & Sodium benzene disulphonate & \\
\hline & Sodium cinnamate & $-\mathrm{COO}^{-} \mathrm{Na}^{+}$ \\
\hline & Sodium3-hydroxy-2-naphthoate & \\
\hline & Sodium para toluene sulphonate. & \\
\hline & Sodium cumene sulphonate & \\
\hline \multirow[t]{4}{*}{ Aromatic cationics } & & \\
\hline & Para amino benzoic acid hydrochloride & \\
\hline & Procaine hydrochloride & \\
\hline & Caffeine & \\
\hline Aliphatics and linear anionics & Sodium alkanoate & $\mathrm{CH}_{3}-\left(\mathrm{CH}_{2}\right)_{\times}-\mathrm{COO}^{-} \mathrm{Na}^{+}$ \\
\hline
\end{tabular}

Flow Chart1. Preparation of hydrotropic solid dispersion

Distilled water $\left(80-85^{\circ} \mathrm{C}\right)$

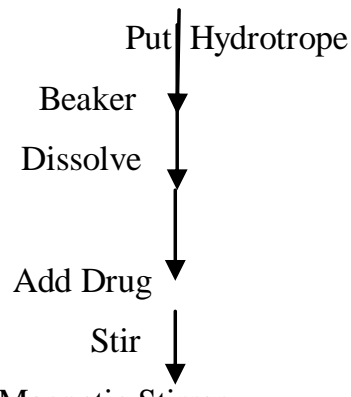

In Magnetic Stirrer

Formation of Semisolid Mass

Poured on watch glass

Keep in Oven $\left(60-65^{\circ} \mathrm{C}\right)$

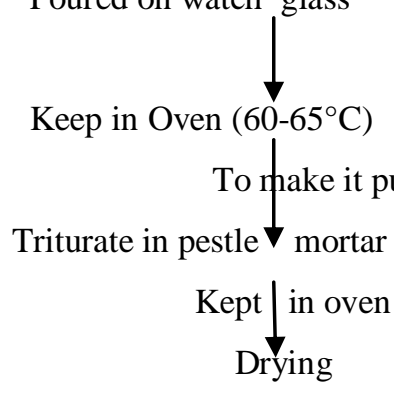




\section{MIXED HYDROTROPY}

It is a solubilization technique to increase the water solubility of poorly water soluble drugs by using different ratio of blends of hydrotropic agents which gives synergistic enhancement effect. The main advantage of this technique is that it reduces the concentration of individual hydrotropic agents which directly reduces the side effects of individual hydrotropic agent. A novel, safe and sensitive method of spectrophotometric determination of Hydrochlorothiazide in tablets was developed using mixed hydrotropic solubilisation technique and concluded that there is enhancement of solubility up to 25 folds by mixed hydrotropy. Hydrotropic solid dispersion of aceclofenac was formulated and evaluated by using six blends of hydrotropes (urea and sodium citrate) and concluded that solubility of aceclofenac increases synergistically by mixed hydrotropic solublization technique. $^{27}$

A further study was analyzed by using mixed hydrotropy on nitazoxanide, using sodium benzoate and sodium salicylate as hydrotropic agents and accomplished that there is enhancement of solubility up to 12 folds. ${ }^{28}$

Various drugs have been enlisted here whose solubility has been enhanced by use of hydrotropes which is presented in Table 4.

Table 4: Solubility enhancement of poorly water soluble drugs by using hydrotrope

\begin{tabular}{|l|l|l|l|}
\hline Drugs Name & Category & Hydrotropes Used & Solubility Enhancement \\
\hline Curcuminoids $^{29}$ & $\begin{array}{l}\text { Natural } \\
\text { compound(Phenolic) }\end{array}$ & $\begin{array}{l}\text { Sodium Salicylate, Sodium } \\
\text { Benzoate, Resorcinol. }\end{array}$ & 144 times \\
\hline Chartreusin $^{30}$ & Cytotoxic agent & $\begin{array}{l}\text { Sodium Benzoate, Sodium } \\
\text { trihydroxy Benzoate. }\end{array}$ & Solubility enhanced. \\
\hline Cefadroxil $^{32}$ & Antibiotic (Cephalosporin) & Urea & 10 times \\
\hline Glipizide $^{32}$ & Antidiabetic & $\begin{array}{l}\text { SodiumBenzoate, Sodium acetate, } \\
\text { Sodium salicylate. }\end{array}$ & 55 times \\
\hline Fenofibrate $^{33}$ & Lipid lowering drug & Urea, Sodium citrate & 233 times \\
\hline Aceclofenac $^{34}$ & NSAIDS & Urea, Sodium citrate & 250 times \\
\hline $\begin{array}{l}\text { Pramipexole } \\
\text { Dihydrochloride }^{35}\end{array}$ & Antiparkinson & Urea, Sodium acetate & 46 times \\
\hline Pacilitaxel $^{36}$ & Anticancer & $\begin{array}{l}\text { N N Diethyl Nicotinamide, } \\
\text { N N Dimethyl Benzamide }\end{array}$ & Solubility enhanced. \\
\hline Losarton $^{37}$ & Antihypertensive & Sodium chloride & 63 times \\
\hline Simvastatin $^{37}$ & Antihyperlipidemic & Sodium chloride & 90 \\
\hline $\begin{array}{l}\text { Tenfovir Disoproxil } \\
\text { Fumerate }^{38}\end{array}$ & Antiretroviral & Sodium Benzoate & 112 -121 times \\
\hline Metronidazol $^{39}$ & Antiprotozoal & Sodium Benzoate & 5 times \\
\hline Tinidazole $^{39}$ & Antiparasitic & Sodium Benzoate & 6 times \\
\hline Norfloxacin $^{39}$ & Antibiotic & Sodium Benzoate & 40 times \\
\hline Nalidixic acid $^{39}$ & Antibiotic & Sodium Benzoate & 98 \\
\hline Ketoprofen $^{40}$ & NSAIDS & $\begin{array}{l}\text { Urea, Sodium Acetate, Sodium } \\
\text { Citrate }\end{array}$ & 570 times \\
\hline Indomethacin $^{41}$ & NSAIDS & Sodium p-hydroxy benzoate & 117.5 times \\
\hline Amlodipine Besylate $^{42}$ & Antihypertensive & Urea & 7 times \\
\hline Benzoic acid $^{43}$ & Antifungal, Antibacterial & Sodium benzoate, Sodium salicylate & $\begin{array}{l}14 \text { fold enhancement with } \\
\text { sodium benzoate and } 28\end{array}$ \\
\hline Pacilitaxel $^{44}$ & Anticancer & Hydrotropic polymer and hydrogel & Solubility enhanced \\
\hline
\end{tabular}

\section{REFERENCES}

1. Gaud and Gupta. Practical physical pharmacy. $3^{\text {rd }}$ ed. CBS Publications. 2003. p.106-107.

2. Aulton ME. Pharmaceutics, The sciences of dosage form design, $2^{\text {nd }}$ ed. P. 22.

3. Brahmankar DM and Jaiswal SB. Biopharmaceutics and pharmacokinetics - A Treatise. $2^{\text {nd }}$ ed. Vallabh Prakashan, New Delhi. 1995. p. 345-346.

4. Wu CY, Benet LS, Predicting drug disposition via application of BCS: Transport /Absorption elimination interplay \& development of a biopharmaceutical drug disposition classification system, Pharm Res, 2005, 22(1), 23-27.

5. Gibson. Pharmaceutical preformulation and formulation. $2^{\text {nd }}$ ed. Interpharm Press. 2001. p. 28-29.
6. Martin A. Micromeritics in physical pharmacy. $2^{\text {nd }}$ ed. Phikadelphia PA.1988. p.273.

7. Goel A, Sharma M, Sharma S, Haffez A, Arora J, Pharmacokinetic data and solubility profile of antihypertensive drugs, Int J Pharma Prof Res, 2010, 1, 61-77.

8. Goel A, Saini S, Chowdhry V, Haider SA, Singh RK, Pharmacokinetic solubility and dissolution profile of anticancer drugs, Int J Pharma Prof Res, 2011, 2, 4, 502-539.

9. Goel A, Aggarwal S, Partap S, Saurabh A, Choudhary V, Pharmacokinetic solubility and dissolution profile of antiarrythmic drugs, Int J Pharma Prof Res, 2012, 3, 1, 592601. 
10. Jain P, Goel A, Sharma S, Parmar M, Solubilty enhancement techniques with special emphasis on hydrotropy, Int J Pharma Prof Res, 2010, 1, 34-44.

11. Seedher $N$ and Aggarwal P, various solvent systems for solubility enhancement of enrofloxacin, Ind J Pharm Sci, 2009, 71, 1, 82-87.

12. Jason MV, Williams RO, Johnston KP, Formulation of danazol micronized by evaporative precipitation into aqueous solution, Bio aqueous solubilization service, Dowpharma, www.dowpharma.com.

13. Patel JN, Rathod DM, Patel NA, Modasiya MK, Techniques to improve the solubility of poorly soluble drugs, Int J Pharm Life Sci, 2012, 3, 2, 1459-1469.

14. Das A, Nayak AK, Mohanty B, Panda S, solubility and dissolution enhancement of etoricoxib by solid dispersion technique using sugar carriers, Int Sch Res, 2011, 1-8.

15. Samy AM, Marzouk MA, Ammar AA, Ahmed MK, enhancement of the dissolution profile of allopurinol by a solid dispersion technique, Drug Discov Therap, 2010, 4, 2, 77-84.

16. Ghareeb MM, Abdulrasool AA, Hussein AA, Noordin MI, Kneading technique for preparation of binary solid dispersion of meloxicam with poloxamer 188, AAPS Pharm SciTech, 2009, 10, 4, 1206-1215.

17. Krishnamoorthy V, Nagalingam A, Prasad VPR, Parameshwaran S, George $\mathrm{N}$ et. al. Characterization of olanzapine-solid dispersions, Iranian J Pharm Res, 2011, 10, 1, 13-24.

18. Jalalia MB, Valizadeha H, Dastmalchic S, Shadbada MRS, Jalalie AB et.al. Enhancing dissolution rate of carbamazepine via cogrinding with crospovidone and hydroxypropylmethyl cellulose, Iranian J Pharm Res, 2007, 6, 3, 159-165.

19. Bajaj H, Bisht S, Yadav M, Singh V, Bioavailability enhancement: A review, Int J Pharma Bio Sci, 2011, 2, 2, 202 216.

20. Ain S, Ain Q, Parveen S, an overview on various approaches used for solubilization of poorly soluble drugs, T Pharm Res, 2009, 2, 84-104.

21. Patel R, Patel M, Shah D, Applications of cyclodextrin in drug delivery, Int J Pharm World Res, 2011, 1, 2, 1-22.

22. Zaheer A, Naveen M, Santosh MK, Imran K, Solubility enhancement of poorly water soluble drugs, Int J PharmTech, $2011,3,1,807-823$.

23. Nidhi $K$, Indrajeet $S$, Khushboo $M$, Gauri $K$, Sen DJ, Hydrotropy: a promising tool for solubility enhancement, Int J Drug Dev Res, 2011, 3, 2, 26-33.

24. Stig E, Fribergand \& Irena Blute, Liquid Detergents. Edited by Kuo-yann lai, CRC Press. 2005. p.19-38.

25. Maheshwari RK, Chavada V, Varghese S, Shahoo K, Analysis of bulk sample of salicyclic acid by application of hydrotropic solubilization method, Ind J Pharm Sci, 2008, 70, 6, 823-825.

26. Maheshwari RK, Deswal S, Tiwari D, Ali N, Pothen B et al, Novel spectrophotometric estimation of frusemide using hydrotropic solublization phenomenon, Ind J Pharma Sci, 2007, 69, 6, 822-824.

27. Maheshwari RK, Indurkhya A, Novel application mixed hydrotropic solublization technique in the formulation and evaluation of hydrotropic solid dispersion of aceclofenac, Asian J Pharm, 2010, 2, 4, 235-238.
28. Sherje AP, Rahigude A, Warma S, Vanshiv SD, Mixed hydrotropy in spectrophotometric analysis of nitazoxanide, Int J Chem. Tech. Res, 2010, 2, 1965-1969.

29. Sreenivasan D, Jayakumar C, Gandhi NN, Effect of hydrotropes on solubility and mass transfer co-efficient of curcuminoids, J Pharm Res, 2010, 3, 9, 2170-71.

30. Poochikian GK, Cradock JC, Enhanced chartreusin solubility by hydroxybenzoate hydrotropy, J Pharm Res, 1979, 68, 6, 2170-71.

31. Shukla RS, Patel A, Soni ML, Modi V, Jaliwala YA, Quantitative spectrophotometric estimation of cefadroxil using hydrotropic solubilization, Asian J Pharm, 2008, 146-148.

32. Shukla M, Rathore P, Jain A, Nayak S, Enhanced solubility study of glipizide using different solubilization techniques, Int J Pharmacy Pharmac Res, 2010, 2, 2, 46-48.

33. Badjatya JK, Bodla RB, Moon UB, Enhancement of solubility of fenofibrate by using different solubilization techniques, Asian J Pharmacy Life Sci, 2011, 1, 2, 144-148.

34. Maheshwari RK, Arif D, Manchandani P, Indurakhya A, Jawade S, A novel method for quantitative determination of aceclofenac in bulk drug and tablet using ibuprofen sodium as hydrotropic solubilizing agents, J Applied Chem Res, 2008, 5 63-68.

35. Jain N, Jain R, Kulkarni S, Jain DK, Jain S, Ecofriendly spectrophotometric method development and their validation for quantitative estimation of pramipexole dihydrochloride using mixed hydrotropic technique, J Chemical Pharma Res, 2011, 3, 1, 548-552.

36. Lee J, Lee SC, Acharya G, Chang C, Park K, Hydrotropic solubilization of pacilitaxel: analysis of chemical structures for hydrotropic property, Pharma Res, 2003, 20, 7, 1022-1030.

37. Sable PN, Chaulang GM, Bhosale AV, Novel spectrophotometric estimation of izetemib, losartan and simvastatin using hydrotropic solubilizing agents, Int $\mathrm{J}$ Chemtech Res, 2009, 1, 4, 1393-1397.

38. Sharma MC, Sharma S, Sharma AD, Hydrotropic solubilization phenomenon spectrophotometric estimation of tenfovir disoproxil fumerate tablet, J Chemical Pharm Res, 2010, 2, 2, 411-415.

39. Maheshwari RK, Chaturvedi SC, Jain NK, Novel spectrophotometric estimation of some poorly soluble drugs using hydrotropic solubilizing agents, Ind J Pharma Sci, 2006, 68, 2, 195-198.

40. Nair V, Rajput MS, A simple spectrophotometric estimation of ketoprofen in tablets using mixed hydrotropy, Sch Res Lib, 2010, 2, 2, 267-271.

41. Jain AK, Solubilization of Indomethacin using hydrotropes for aqueous injection, Eur J Pharm Biopharm, 2008, 68, 701-714.

42. Bernard S, Mathew M, Senthilkumar KL, Spectrophhotometric method of estimation of amlodipine besylate using hydrotropic solubilization, J Applied Pharm Sci, 2011, 1, 9, 177-180.

43. Maheshwari RK, Singh RM, Yamini MVS, Amit G, Quantitative estimation of benzoic acid in bulk sample using sodium benzoate and sodium salicylate as hydrotropic solubilizing agent, T Pharm Res, 2009, 2, 1-7.

44. Park K, Ghansyam A, Lee J, Lee SC, Pharmaceutical application of hydrotropic agents, polymers thereof, and hydrogels thereof. United States Patents Publication US 2003/0031715A. 